\title{
Eine scharfe Sache
}

\section{Iris Ritzmann}

Prof. Dr. med. et lic. phil., Mitglied der Redaktion Medizingeschichte

Im Jahr 1543 gab der Medizinprofessor und Lutheranhänger Leonhart Fuchs (1501-1566) sein deutschsprachiges New Kreüterbuch heraus. Der farbenfrohe Holzschnitt «Langer Indianischer Pfeffer» stammt aus einer überaus sorgfältig kolorierten Erstausgabe. Die länglichen Früchte in dunklem Grün und leuchtendem Rot lassen sich unschwer als Chilischoten identifizieren, die heute sowohl in der internationalen Küche als auch in der Rheumatologie ihre Verwendung finden. 1543 aber war die Pflanze noch weitgehend unbekannt. Sie wurde erst seit wenigen Jahren in Europa angepflanzt, weshalb Fuchs genaue Anweisungen erteilt, wie sie in der kalten Jahreszeit zu halten sei.

Die Wirkung des Indianischen Pfeffers beschreibt Fuchs ganz im Denkstil der humoralpathologischen Logik: Die Pflanze sei heiss und trocken, wirke deshalb gut gegen einen kalten Magen, Verstopfung und Blähungen. Durch die trockene Wärme löse sie stockende Säfte, bringe also die Humores wieder ins Gleichgewicht. Äusserlich aufgetragen könne der Indianische Pfeffer mit seiner brennenden Hitze Wundfäulnis, Hautflechten und Unreinheiten vertreiben. Innerlich sei er ein probates Mittel gegen Zahnschmerzen, eine Anwendung, die sich auch in der aztekischen Medizin nachweisen lässt.

\section{Leonhart Fuchs hatte sich zum Ziel gesetzt, Ärzten, Apothekern, aber auch Laien eine Vorlage zur eindeutigen Zuordnung jeder Arzneipflanze an die Hand zu geben.}

512 Pflanzen nahm Fuchs in sein Kreüterbuch auf. Der Indianische Pfeffer zählt zu den rund hundert Erstbeschreibungen, von denen viele aus der «Neuen Welt» stammten. Einige Pflanzen hatten bereits zuvor Hieronymus Bock und Otto Brunfels, die mit Fuchs zusammen als die drei «Väter der Botanik» bezeichnet werden, in ihren Werken beschrieben.

Fuchs hatte sich zum Ziel gesetzt, Ärzten, Apothekern, aber auch Laien eine Vorlage zur eindeutigen Zuordnung jeder Arzneipflanze an die Hand zu geben. Deshalb musste jede Pflanze möglichst naturgetreu mit Blüten, Früchten, Blättern und Wurzeln auf den Holzschnitten und in den Texten zu erkennen sein. Der Autor beaufsichtigte den Zeichner persönlich und

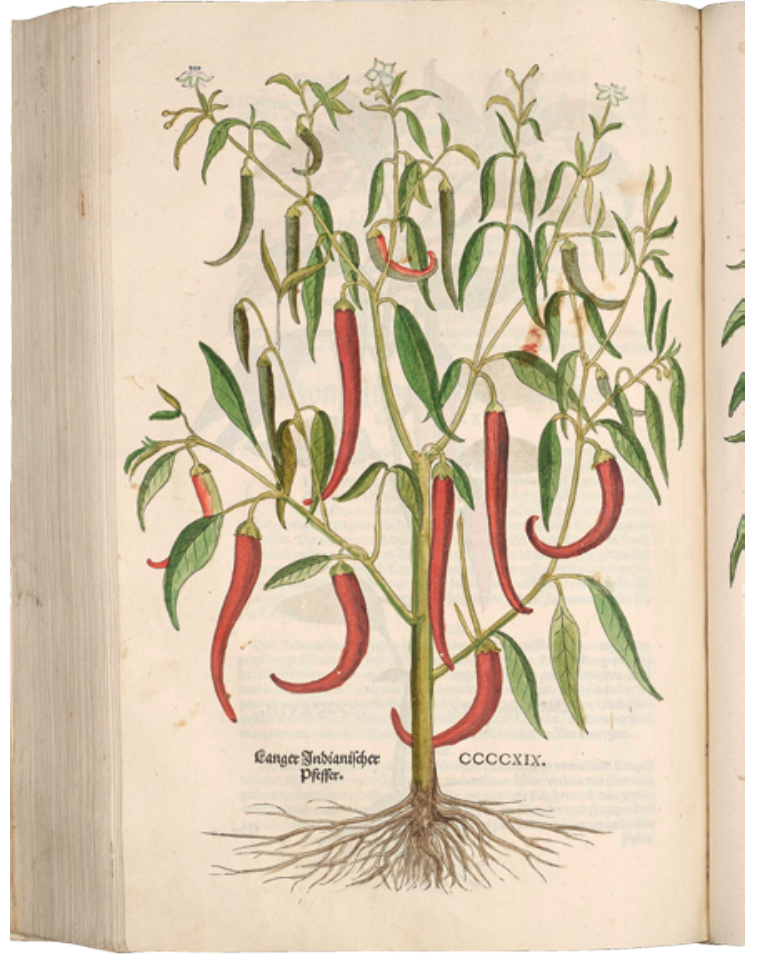

Leonhart Fuchs, New Kreüterbuch, Tafel 419: «Langer Indianischer Pfeffer», Basel 1543, Sammlung Dr. Franz Käppeli.

stellte an die Ausführung der Holzschnitte höchste Ansprüche.

Im selben Jahr, als das Kreüterbuch erschien, erschütterte die Publikation von Kopernikus das geozentrische Weltbild, und traditionelle Körpervorstellungen erfuhren mit der Erstausgabe von Vesals Fabrica eine tiefschneidende Umorientierung. Und dennoch baute das Kreüterbuch von Leonhart Fuchs, wie andere Umwälzungen der Renaissance auch, auf bereits vorhandenem Wissen auf. Fuchs erweiterte die alte europäische Pharmakopöe mit detailgetreuen Darstellungen einheimischer und amerikanischer Pflanzen, ohne die Viersäftelehre in Frage zu stellen. Das Kreüterbuch brach nicht mit der Vergangenheit und prägte dennoch die zukünftige Entwicklung der Kräuterkunde. Nicht nur der "Indianische Pfeffer», das ganze Werk ist somit eine scharfe Sache.

Bildnachweis

Museum für medizinhistorische Bücher Muri (mmbm.ch) 